NBER WORKING PAPER SERIES

\title{
DECOMPOSING WAGE INEQUALITY CHANGE USING GENERAL EQUILIBRIUM MODELS
}

\author{
Lisandro Abrego \\ John Whalley \\ Working Paper 9184 \\ http://www.nber.org/papers/w9184
NATIONAL BUREAU OF ECONOMIC RESEARCH
1050 Massachusetts Avenue
Cambridge, MA 02138
September 2002

This paper is part of a project on Globalization and Social Exclusion supported by the EU. We are grateful to Huw Edwards, Carlo Perroni, and Dan Treffler for comments, and to seminar participants at Toronto and Warwick. The main parts of this paper were written while the first author was at the University of Warwick. The views expressed are personal and not necessarily those of the International Monetary Fund or the National Bureau of Economic Research.

(C) 2002 by Lisandro Abrego and John Whalley. All rights reserved. Short sections of text, not to exceed two paragraphs, may be quoted without explicit permission provided that full credit, including (C) notice, is given to the source. 
Decomposing Wage Inequality Change Using General Equilibrium Models

Lisandro Abrego and John Whalley

NBER Working Paper No. 9184

September 2002

JEL No. J3, D5

\begin{abstract}
This paper presents _ex post decomposition analysis of wage inequality change using multisector general equilibrium models. The analytical structure used is a specific-factors model of trade, which we calibrate to UK data for the two years 1979 and 1975 . We first calibrate our general equilibrium trade model to observations on wage inequality, trade, production and consumption spanning these years, capturing the separate influences of trade, technology and demographics on inequality. Between these years wage inequality changed, but multiple changes in exogenous variables occurred (world prices, technology, endowments). We use calibration techniques to determine parameter values consistent with both the equilibria and the changes in exogenous variables contributing to the wage inequality change being decomposed. We then compute counterfactual equilibria in which only some of the changes in exogenous variables are present to allow us to assess what portion of the observed change is attributable to the various contributing factors. Our findings are that the roles of trade and factor-biased technological change are relatively larger than in earlier literature. We also find that changes in factor endowments to offset increased inequality generated by trade and skilled-biased technological changes, a feature that seems to have gone relatively unnoticed in earlier literature.
\end{abstract}

Lisandro Abrego

International Monetary Fund
John Whalley

Department of Economics

Social Science Centre

University of Western Ontario

London, Ontario N6A 5C2

Cananda

and University of Warwick

and NBER

jwhalley@julian.uwo.ca 


\section{Introduction}

Economists have long been interested in decomposing observed economic outcomes driven by multiple factors into parts attributable to each. This is the case in both the growth accounting literature (Solow, 1957), and the economic history literature (Fogel (1964), for instance). The majority of these exercises focus on identifying the separate role played by a few key factors presumed to be the main sources behind the outcome, typically leaving a residual as attributed to factors not explicitly modelled. How to decompose observed economic outcomes has been little studied in the applied general equilibrium literature (see Shoven and Whalley, 1992). Models have, instead, largely been used for ex-ante counterfactual exercises of anticipated policy changes, whose outcome has not been observed.

In this paper, we report on an ex-post general-equilibrium calibration methodology which we use to decompose observed economic outcomes generated by multiple sources into components attributed to each source, and apply it to the trade-technology debate on the causes of increased OECD wage inequality (Leamer, 2000; Krugman, 2000). We decompose observed (ex-post) economic outcomes into portions attributed to component influences, rather than computing ex-ante counterfactual equilibria, recognizing that these influences need not be and typically will not be additive. We base our analysis on multiple-period rather than single period calibration, since model parameterisations need to be consistent with changes over time, not just a base year observation. Our calibration to initial- and terminal-year data may be either exact or inexact (see Dawkins, Srinivasan, and Whalley, 2000), depending on the restrictions imposed.

The model structure we use is a specific-factors (or Ricardo-Viner) trade model, which differs from a more standard Heckscher-Ohlin-type structure through the presence of specific factors that are immobile across sectors, and hence yields decreasing returns to scale to the 
mobile factors. The traditional Heckscher-Ohlin model with fully mobile factors and constant returns to scale, when used with conventional functional forms (such as CES), cannot accommodate relative product-price changes of the magnitude that have been observed along with increased wage inequality in countries such as the US or the UK (see OECD, 1997; Abrego and Whalley, 2000). This is due to the near linearity of the transformation frontier associated with this model structure and the ensuing problems of full specialisation documented some years ago by Johnson (1966). For the small open economy case, the standard Heckscher-Ohlin model is also unable to accommodate factor-biased technical change as a source of relative wage change (Leamer, 1998; Krugman, 2000). This is unsatisfactory since the available empirical evidence seems to support the hypothesis that factor-biased technical change has been a major source of increased OECD wage inequality. A fixed-factors model eliminates the full specialisation problems, produces relative wage changes under factor-biased technical change, and hence can be used for decomposition of inequality change.

We apply these techniques to a component decomposition of increased wage inequality over the 1980s and 1990s as has occurred for a number of OECD countries such as the US and the UK (e.g. Gottschalk and Smeeding, 1997; Slaughter, 1999). The literature on recent increases in wage inequality has concentrated on two main contributing factors---trade with low-wage countries, and technological change. Most literature concludes that technological change is the main source of this increased inequality, rather than trade (Bound and Johnson, 1992; Baldwin and Cain, 1997; Feenstra and Hanson, 1999). The model and the techniques we present here suggest that, within a general equilibrium setting, other factors, such as changes in endowments and a wider variety of technical change, also enter the picture and can play a significant role. 
The paper is organised as follows. The next section briefly reviews the literature on wage inequality and decompositional analysis. Section 3 present our model and calibration procedures. Section 4 describes our data, while Section 5 presents and discusses results. Section 6 concludes. 


\section{Background}

The motivation for our decomposition analysis is the extensive literature which tries to attribute portions of recent OECD wage inequality change to various contributory factors. Little or none of this conducts decompositions using the explicit equilibria structures which dominate related trade theoretic literature; rather, reduced-form econometrics motivated by quantitative theory are used.

In this literature, most attention has been paid to two factors behind increased inequality; trade with low-wage countries and factor-biased technical change (e.g. Burtless 1995; Slaughter, 1999). Some literature has also looked at the contribution of changes in relative factor supplies (e.g. Bound and Johnson, 1992; Baldwin and Cain, 1997) as well as of changes in labour market institutions (e.g. Fortin and Thomas, 1997; Card, 1998; Machin and van Reenen, 1998). With only a few exceptions (Wood, 1994; Feenstra and Hanson, 1996), this work has concluded that the contribution of trade to increased OECD wage inequality has been small, with technical change playing the more important role. Empirical evidence on the role of changes in factor supplies is conflicting, and sometimes statistically insignificant. ${ }^{1}$ Some studies (Gottschalk and Smeeding, 1997; Card, 1998; Machin and van Reenen, 1998) have also reported a substantial role for changes in labour market institutions. Some limitations of the reduced-form econometric methodologies used have been discussed in Abrego and Whalley (2000), who point out that multiple structural-form specifications are available which are consistent with observed changes, but each provide different decomposition results. Also, technological change has been treated in this literature in different ways; as a residual in Solow-type (Solow, 1957) (sectoral) growth-

\footnotetext{
${ }^{1}$ See for example, Murphy and Welch (1989); Bound and Johnson (1992); Baldwin and Cain (1997); and Harrigan and Balaban (1999).
} 
accounting framework (Leamer, 1996; Harrigan and Baliban, 1999); as the change in R\&D expenditure (e.g. Machin and van Reenen, 1998; Anderton and Brenton, 1998); as the change in a factor's cost share not explained by the factor price change (e.g., Berman, Bound and Griliches, 1994; Haskel and Slaughter, 1998); or merely as the factor that is left in determining the wage inequality change after trade is taken into account (Abrego and Whalley, 2000). An advantage of the techniques that we use here is that the measure of technical change determined through such calibration is fully consistent with the model structure being used and the observed equilibria.

Two earlier papers have reported on more limited decomposition-type experiments than here, also using multi-sector general equilibrium models (e.g. Abrego and Whalley, 2000; Francois and Nelson, 1998). One weakness of earlier procedures is that if the second counterfactual equilibrium is unconstrained, except for consistency with the wage inequality change (as in Abrego and Whalley, 2000), model solutions will not generally correspond to observed data for both periods. The wage change may be replicated but trade, output, employment and consumption changes will not. Our procedures are aimed at remedying these weaknesses. Our decompositions involve changes over time in the relative wages of skilled and unskilled labour. These are accompanied by both trade changes (reflected in changes in the terms of trade) and technology changes (which may be sector or factor biased), and the issue is the contribution of each factor. Decomposition proceeds by calibrating an explicit general equilibrium model to the data for the years in question, and then computing counterfactual equilibria with or without the added influence of trade and/or technological change. These computations aim to isolate the influence of each of the factors. 


\section{A Calibrated Model For Use in Decomposition}

For our decomposition analysis we use a model of a small open, price-taking economy calibrated to data for the UK for two years (1979 and 1995). We use a Ricardo-Viner specificfactors model, in contrast to a Hecksher-Ohlin-type, fully-mobile factors model.

During the period we study, substantial increase in wage inequality occurred. The issue is what portion of the observed change can be attributed to import surges of low-wage goods and which to technical change. Most of the recent empirical literature assessing the importance of factors contributing to increased wage inequality notes that OECD countries generally import low-skill intensive goods, and export high-skill intensive goods.

The attraction of using Heckscher-Ohlin-type models to earlier researchers in this area has been that they provide a simple and widely used analytical framework in which the relationship between relative wages and relative price changes is clearly defined. But for widely used functional forms, the Heckscher-Ohlin model (with homogeneous goods and constant returns to scale) has problems in accommodating relatively large product price changes (Abrego and Whalley, 2000). This is due to the near linearity of the transformation frontier implied by the model, and the ensuing problems of complete specialisation following relative price changes (Johnson, 1966). Conventional Heckscher-Ohlin structures are also incapable of accommodating factor-biased technical change as a source of wage change for the small open economy case (Leamer, 1998; Krugman, 2000).

Although Armington (country differentiated product) models have been widely used in the applied general equilibrium literature, they are harder to work with analytically and hence no general results linking changes in relative prices with relative wages are available from them. Using a specific factors trade model (Ricardo-Viner) with decreasing returns to scale, a structure 
that has been more widely explored in the analytical literature of international trade (Jones, 1971; Samuelson, 1971; Mussa, 1974), yields decreasing returns in each sector with respect to a composite of mobile skilled and unskilled labour. We model fixed factors in each sector of 2 sectors (skilled and unskilled labour intensive) as well as 2 fully-mobile factors (skilled and unskilled labour).

\subsection{Production}

We treat the UK as a small open, price-taking economy that produces two goods, $M$ and $E$, both of which are traded at fixed world prices $\left(P_{i t} ; i=M, E\right)$, in period $t$. The production of each good in each period requires the use of two mobile factors: skilled labour, $S$, and unskilled labour, $U$, along with a sector-specific fixed factor. Production, consumption and trade take place in each of the two time periods, 1 and 2, which we refer to as the initial and terminal periods.

Thus, each good in each period is produced according to a decreasing returns to scale technology:

$$
Y_{i t}=A_{i t} L_{i t}^{\alpha_{i t}}, \quad i=M, E ; t=1,2
$$

where $Y_{i t}$ represents output of good $i$ in period $t, A_{i t}$ denotes a sector-specific efficiency measure of a composite labour factor input, and $L_{i t}$ is use of a composite labour input. $\alpha_{i t}$ is the output elasticity with respect to composite labour, assumed to be strictly less than one to yield decreasing returns to scale. Consistent with a Ricardo-Viner approach, (1) implicitly defines a fixed factor in production in each sector, with a Cobb-Douglas share $\left(1-\alpha_{i t}\right)$.

The composite labour input in each sector, $L_{i t}$, is, in turn, a CES aggregate of unskilled and skilled labor, $U$ and $S$, 


$$
L_{i t}=B_{i t}\left[\beta_{i t}\left(\delta_{t}^{U} U_{i t}\right)^{\left(\rho_{i t}-1\right) / \rho_{i t}}+\left(1-\beta_{i t}\right)\left(\delta_{t}^{S} S_{i t}\right)^{\left(\rho_{i t}-1\right) / \rho_{i t}}\right]^{\frac{\rho_{i t}}{\rho_{i t}-1}}, \quad i=M, E ; t=1,2
$$

where $B_{i t}$ defines units for composite labor used in sector $i$ in period $t$, and $\beta_{i t}$ is the CES share parameter in the aggregation function. $\delta_{t}^{U}$ and $\delta_{t}^{S}$ are factor-augmenting technical change parameters which capture changes in input quality over time. $\rho_{i t}$ denotes the elasticity of substitution in sector $i$ in period $t$ between unskilled and skilled labor.

Combining (1) and (2) for each sector in each period yields

$$
Y_{i t}=\gamma_{i t}\left[\beta_{i t}\left(\delta_{t}^{U} U_{i t}\right)^{\left(\rho_{i t}-1\right) / \rho_{i t}}+\left(1-\beta_{i t}\right)\left(\delta_{t}^{S} S_{i t}\right)^{\left(\rho_{i t}-1\right) / \rho_{i t}}\right]^{\alpha_{i t} \rho_{i t}-1}, \quad i=M, E ; t=1,2
$$

where the units parameter in the consolidated function (3) $\gamma_{i t}=A_{i t} B_{i t}$. In (3), changes in $\gamma_{i t}$ represent sector-specific, Hicks-neutral technical change, while $\delta_{t}^{U}$ and $\delta_{t}^{S}$ reflect factor-biased technical change. In our empirical implementation of this model, we assume that (as in most OECD economies) production of the importable good, $M$, is intensive in unskilled labour in both periods, i.e. $\beta_{M t}>\beta_{E t} \forall t$.

\subsection{Labour Markets}

Competitive labour markets are assumed, so that each type of labour is paid its marginal value product, with full employment of each type of labour in each period. The endowments of unskilled and skilled labour, $\bar{U}_{\mathrm{t}}$ and $\bar{S}_{\mathrm{t}}$ respectively, are assumed to be fixed in each time period, while varying across periods.

First order conditions for factor demands implied by marginal product pricing are

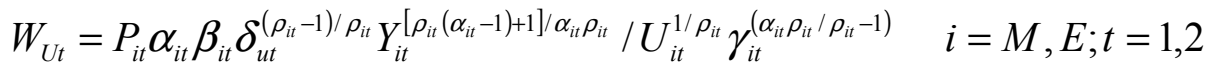

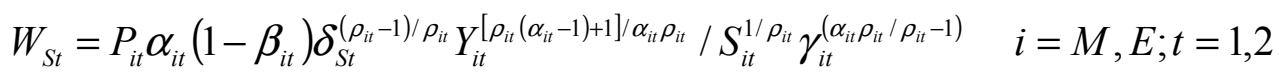


where $W_{U t}$ and $W_{S t}$ denote unskilled and skilled wage rates respectively, and $P_{i t}$ is the (fixed) world prices of good $i$ in period $t$. Given the decreasing returns technology set out in (1), payments to unskilled and skilled labour do not exhaust the value of production in either sector, and the remaining factor income implied by (1) accrues to the fixed factor in each sector.

\subsection{Trade}

We model trade shocks in this framework as changes in world prices, which, in turn, typically induce increased import volumes. Here, we consider the shock to be a fall in the relative price of unskilled intensive to skill intensive goods between the initial and terminal years. These generate larger import volumes in the model, adjustment of labour out of the unskilled intensive sector, and increases in exports.

In equilibrium a zero trade balance condition holds, i.e.,

$$
\sum_{i=M, E} P_{i t} T_{t i}=0
$$

where $T_{i t}$ denotes the net trades of the country in the two goods, $M$ and $E$. The sign convention is that if good $i$ is exported, domestic production less consumption is positive; if good $i$ is imported this difference is negative. Imports and competitive domestically produced goods are treated as homogeneous, as is also assumed to be the case with exports. This homogeneity assumption implies that trade flows involving any good are always one-way, and that one of the goods is exported and the other imported.

\subsection{Equilibrium Conditions}

Given the small open economy assumption underlying the model, goods markets do not clear domestically. Imports and exports reflect positive and negative excess demands which are 
absorbed or met by world markets subject to trade balance, with the small economy facing perfectly elastic demands and supplies at world prices.

Equilibrium in each period in this model is given by unskilled and skilled wage rates such that the two domestic labour markets clear. The value marginal product of each mobile factor in each sector is equal to the corresponding wage rate, as in (4) and (5), and the fixed factor in each sector $i$ receives the residual in return, $F_{i t}$, in period $t$. Market clearing conditions of this form hold in both periods, i.e.

$$
\begin{aligned}
& \sum_{i} U_{i t}=\overline{U_{t}}, \quad i=M, E ; t=1,2 \\
& \sum_{i} S_{i t}=\overline{S_{t}}, \quad i=M, E ; t=1,2
\end{aligned}
$$

The two market-clearing conditions (7) and (8) determine the equilibrium wage rates for skilled and unskilled labour. The fixed factor in each sector receives the difference between the value of production at world prices and payments to mobile factor inputs. This enters incomes which, in turn, finance goods demands.

Consumption of each good in equilibrium is given by the difference between production and net trade, i.e.

$$
C_{i t}=Y_{i t}-T_{i t}, \quad i=M, E ; t=1,2
$$

where $C_{i t}$ denotes consumption of good $i$ in period $t$. A property of equilibrium in such a model (from Walras Law) is that trade balance will be satisfied.

\subsection{Model Calibration}

Calibration is now a widely used technique for specifying numerical values of parameters in general equilibrium simulation (see Dawkins, Srinivasan, and Whalley, 2000). Usually, in micro-based models used to evaluate policy options on an ex-ante basis, calibration occurs in so 
called levels form to a single, model-consistent equilibrium data set constructed from observed outcomes. The sub data sets are built from basic data which may violate the model equilibrium conditions, but which is modified for model compatibility (see Shoven and Whalley, 1992). Here, because of our focus on understanding factors behind ex-post changes in key variables (skilled and unskilled wage rates), we need a different calibration procedure; one which is consistent with data which captures the changes in variables over time that are at the heart of the analysis. In this case, it involves two data observations, rather than one as in more conventional calibration.

For the model structure we specify above, our calibration consists of choosing values for model parameters such that the model gives, as far as possible, equilibrium solutions consistent with data in both periods. In the case we consider here, with the small open economy treatment, the demand and production sides of the model are separable. This separability allows us to concentrate only on production function parameters when calibrating since the focus of our decomposition analysis is on determinants of wage rate change, and does not involve demand side considerations ( calibration used here, the demand side of the model is irrelevant to the outcome of the decomposition of wage inequality change.

In single period calibration it is usual to assume that the values of elasticities of substitution in production $(\rho)$ are exogenously given, based on separate literature-based estimation of parameters. Here we also assume that this is the case, but now for both periods. This leaves sixteen production-side parameter values to be determined through calibration; the output elasticities with respect to composite labour, the units terms in sector production 
functions, CES shares in aggregation functions, and factor biased technological change parameters, i.e.

$$
\alpha_{i t}, \gamma_{i t}, \beta_{i t}, \delta_{t}^{U}, \delta_{t}^{S} ; i=M, E ; t=1,2
$$

If these parameters are to be consistent with the model equilibrium conditions in each time period, the values determined for them must satisfy the first order conditions (4) and (5), as well as equation (3). These equations yield a system of 12 equations in 16 unknowns, and to determine parameter values from it we need to introduce additional identifying restrictions.

We first set

$$
\delta_{1}^{U}=\delta_{1}^{S}=1
$$

This is a normalization rule for factor-biased technological change terms, and we can adopt this because it is only changes in technology parameters over time that are relevant in model.

We then impose further restrictions on the model parameterization to yield an equation system for calibration across the two time periods in which the remaining endogenous model parameters are exactly identified. We use three alternative sets of restrictions, each of which yields an exactly identified system of equations from which parameter values for the model are determined. These are

$$
\begin{aligned}
& \text { 1) } \gamma_{i 1}=\gamma_{i 2}, \quad i=M, E \\
& \text { 2) } \delta_{2}^{U}=\delta_{2}^{S}=1
\end{aligned}
$$

or

$$
\text { 3) } \beta_{i 1}=\beta_{i 2}, \quad i=M, E
$$

These three alternatives differ in their implied treatment of technical change over time. Restriction 1 implies that no Hicks-neutral technical change takes place over time. Restriction 2 implies that no factor-biased technical change occurs over time. Restriction 3 allows technical 
change to be both Hicks-neutral and factor-biased, but rules out any change over time in share parameters in the composite CES labour aggregation function. For each of these sets of restrictions, we calibrate the model and assess the implications for decomposition results. We do not restrict the $\alpha_{i t}$ when implementing calibration since these parameter values represent the share of the composite labour input in sectoral income, and must be consistent with the shares implied by the data assembled for each time period.

With this calibration set-up, changes in technology go beyond a simple Hicksneutral/factor-biased classification since other technology-related model parameters can also change. Procedures 1 and 2 leave the $\beta_{i t}$ unconstrained, and therefore subject to variation across time. Under all the calibration procedures listed above, the assumption that the outcome observed in each period constitutes an equilibrium implies that the elasticity of output with respect to the aggregate labour input $\left(\alpha_{i t}\right)$ is also varying through time.

Exact identification of parameter values from model equilibrium conditions does not hold if added restrictions are imposed on parameter values. We therefore also use a further double calibration procedure in which calibration is inexact, rather than exact. In this case, we maintain exact calibration for period 1 . For period 2, parameter values are chosen such that the sum of squared deviations of model-predicted values relative to actual values for endogenous variables is minimized, subject to the full set of general equilibrium constraints. Parameters chosen must be consistent with both optimising behaviour and model equilibrium conditions. Calibration is exact in one period, but inexact in the other because (through equation 11) we set our factorbiased technological change parameters to one in the first period (making the equation system exactly identified for that period), but allow them to be endogenously determined in the second 
period. This units convention could be reversed allowing exact calibration in the second period and inexact calibration in the first period.

To simplify our computations, we implement our inexact calibration procedures only for the case where technical change is assumed to be factor biased; a variant on calibration procedures 1 and 3 above, but with both $\beta_{i t}$ and $\gamma_{i t}$ held fixed over time. In the inexact calibration case, the model-generated equilibrium for period 2 differs from the observed equilibrium, and the model parameterization is determined by minimizing a criterion function.

The objective function minimised in inexact calibration is the sum of squared deviations of model-predicted values relative to observed values for the second period. This criterion is applied to four variables; output, consumption (and hence trade), and employment of the two labour types. We choose values for the two factor-biased technological change parameters $\left(\delta_{2}^{U}, \delta_{2}^{S}\right)$ so as to minimize the criterion function while meeting model equilibrium conditions.

Other criterion functions are possible (such as adding further variable differences between actual and predicted values), although our computational experience indicates that differences in subsequent decomposition results from doing this are small. In our inexact calibration used here, only one additional parameter is restricted relative to exact calibration. Factor endowments and the parameters $\alpha_{i t}$ are given by the data and both vary from period to period, as with exact calibration.

More formally, the optimisation problem solved under this form of inexact calibration is given by

$$
\begin{aligned}
& \min \sum_{i} P_{i 2}\left(Y_{i 2}-\hat{Y}_{i 2}\right)_{t}^{2}+\sum_{i} P_{i 2}\left(C_{i 2}-\hat{C}_{i 2}\right)^{2}+\sum_{i} W_{2}^{S}\left(S_{i 2}-\hat{S}_{i 2}\right)^{2}+\sum W_{2}^{U}\left(U_{i 2}-\hat{U}_{i 2}\right)^{2} \\
& \text { w.r.to } \delta_{2}^{u}, \delta_{2}^{s}
\end{aligned}
$$


s.t. $(3)-(9)$.

Where $\hat{Y}_{i 2}, \hat{C}_{i 2}, \hat{S}_{i 2}$, and $\hat{U}_{1}^{2}$ are model-predicted values in period 2 for output consumption, employment of skilled labour, and employment of unskilled labour. The choice variables are the factor-bias technological change parameters, $\delta_{2}^{u}$ and $\delta_{s}^{s}$. The model first order conditions and equilibrium conditions are given by (3) - (9).

\subsection{Decomposition Experiments}

We have used the model calibrated in each of the ways set out above to generate estimates of the contributions of increased trade, factor-biased technical change, and factor endowment change (demographics) to increases in wage inequality in the UK between 1979 and 1995. We capture trade shocks in our analyses as changes in world prices (the relative price of skill intensive to unskilled intensive goods). These affect trade flows, which are also endogenously determined in the model. We consider the fall in the relative price of the unskilledintensive products (in our case, aggregated under $M$ ) which took place in the UK between 1979 and 1995. Factor-biased technical change over time is modeled as changes in the factoraugmenting technical change parameters, $\delta_{t}^{U}$ and $\delta_{t}^{S}$. We also consider other production function parameter changes generated by the model and calibration procedures as indicated above.

We use the calibrated versions of the model to carry out decomposition experiments using both the exact and inexact calibration procedures described above. In the process, changes in model technology parameters are determined over time using two-period data and the various calibration procedures. The parameter values that are generated change with the procedures implemented. 
For any model parameterization generated by calibration, we assess the contribution to wage inequality of each individual component. We first do this by taking the equilibrium of period 1 as our base model solution, and resolving the model by considering only the trade shock. This allows us to calculate the portions of the total change in wage inequality attributable to this shock. We then change each of the technology parameters implied by the calibration procedure used and repeat the procedures. We finally assess the impact of changes in factor endowments on inequality in a similar manner. These changes taken together are consistent with the observed wage inequality change, as well as other characteristics of the observed period 2 equilibrium.

The proportions of the total change attributed in this way need not (and typically will not) sum to the total change. Each experiment considers a change in only one of three variables, and these variables have interacting effects which imply that their separate contributions may sum to more or less than the observed wage inequality change. The quantitative significance of this nonaddivity property is something revealed by numerical computation. 


\section{Data Used in Decomposition Experiments}

We perform our decomposition experiments using UK data for the two years, 1979 and 1995. This choice of years covers a period during which there was substantial change in wage inequality in the UK, with a near $25 \%$ decline in the ratio of unskilled to skilled wage rates. As Table 1 indicates, there was also a significant increase in real UK GDP, a rise in trade (imports), a roughly constant composition of employment of unskilled and skilled labour by sector, and a sharp rise in the size of the skilled labour pool.

\section{Table 1}

UK data for 1979 and 1995

\begin{tabular}{|c|c|c|}
\hline & 1979 & 1995 \\
\hline UK GDP in 1979 prices (Billion Pounds) & 198 & 262 \\
\hline $\begin{array}{l}\text { Import to gross output ratio for } \\
\text { Unskilled-intensive products }\end{array}$ & 0.129 & 0.173 \\
\hline$\%$ employment in skilled-intensive sector & 48.0 & 49.8 \\
\hline $\begin{array}{l}\text { Ratio of unskilled to skilled labour } \\
\text { Employment aggregate }\end{array}$ & 1.04 & 0.715 \\
\hline $\begin{array}{l}\text { Unskilled to skilled labour wage rate } \\
\text { ratio } \\
\text { ( } 1979 \text { set at } 1.0 \text { as a normalization) }\end{array}$ & 1.0 & 0.769 \\
\hline
\end{tabular}

Source: Office for National Statistics (1997a).

We parameterize the model described in the previous section and apply the double calibration methods set out above. Using double calibration procedures in this way, we fit the model to both initial and end of period observations. Three main issues arise in producing micro consistent data covering each of our two years. One is how to aggregate more detailed and sectorally disaggregated data from original sources into the skilled-unskilled intensive 
breakdown in the model. Another is how to define the returns to skilled and unskilled labour by sector, and to aggregate these factor returns from information on more detailed sectoral classifications. The third relates to the definition of other variables; production, trade, and broader factor incomes.

Following our model structure, we aggregate UK production activities into the two broad sectoral groups of skilled-intensive and unskilled-intensive. Table 2 presents a list of those industries from UK national accounts classifications which we include in each of these two groupings. Sectoral employment of skilled and unskilled workers is taken as given by the use of non-manual and manual workers by industry as reported in the UK Office for National Statistics (ONS) Employment Gazette and Labour Market Trends. Though this measure of skill differentiation is not entirely satisfactory, it has been widely used in other recent wage inequality literature both for the US and the UK (e.g. Sachs and Shatz, 1994; Machin and van Reenen, 1998; Haskel and Slaughter, 1999).

Table 2

UK National Accounts Industries Included in the Skilled (S) and Unskilled (U)-intensive Sectors

\section{S-intensive sector}

Mining and quarrying

Paper and publishing

Petroleum products and nuclear fuel

Chemicals

Machinery and equipment

Electrical and optical equipment

Transport equipment

Electricity, gas and water

Transport, storage and communication

Financial intermediation

Real estate

Public administration, defence

and social security services

\section{U-intensive sector}

Agriculture, hunting and forestry

Food, beverages and tobacco

Textiles and textile products

Leather and leather products

Wood and wood products

Rubber and plastic

Non-metallic minerals

Basic metals and metal products

Other manufacturing

Construction

Trade, restaurants and hotels

Health and social work

Education

Other 
Sectoral production, broad-factor income (labour and capital) and trade data for 1979 come from the UK input-output table for that year (OECD, 1995). We separate manual from non-manual labour income by sector using ONS data on employment and wages for these two groups for the closest available year (1981-82). This data does not split employment and wages by worker type for the sector disaggregation we report in Table 1, and only allows for disaggregation of employment data into manual and non-manual categories for the whole economy. However, from this information, we are able to determine aggregate income for each labour type, and combine this with data on wage rates by skill level to determine sectoral employment and wage bill data for each labour category for 1979.

We use information from ONS sources (for 1981-82 and 1996) to calculate the change in relative hourly wage rates for the period 1979-95. This calculation covers all full-time adult workers in each year, and yields a sizeable relative decline of $23.1 \%$ in the wage of unskilled workers compared to skilled workers. ${ }^{2}$ From Abrego and Whalley (2000) (who, in turn, draw on Neven and Wyplosz, 1999) we use the figure of $7.9 \%$ as the fall in the relative price of the unskilled-intensive good on international markets faced by the UK producers. ${ }^{3}$ This is the trade shock experienced by the UK in the model over the period 1979-95, and enters as an input in our calibration procedures.

Data on production, broad-factor income and trade for 1995 are obtained from the UK input-output table for the year (ONS, 1997b). We use data on sectoral employment and wages by skill category from ONS (1996) to obtain wage bill data for each labour type. Using data on

\footnotetext{
${ }^{2}$ This differs from the 15\% figure used in Abrego and Whalley (2000), because it covers all full-time workers and involves a slightly different time period (Abrego and Whalley's figure is based on male workers only and is for the period 1976-90).

${ }^{3}$ This estimate was based of information in Neven and Wyplozs (1999).
} 
hours worked by sector from the same source, we are able to measure the amount of each labour input used by sector in terms of hours.

When calibrating the model, our data are adjusted such that the terminal year (1995) reflects the observed relative price and wage changes (in real terms). Changes in the value of sector output experienced over the period are similarly adjusted. We employ all this information to parameterize the model using each of the calibration procedures described in the preceding section, including the inexact calibration procedure set out above. We use a base value for the elasticity of substitution between skilled and unskilled labour, $\rho_{i t}$ of 1.25 , which is consistent with input substitution elasticity estimates reported in Hamermesh (1993).

Table 3 reports the 1979 and 1995 model parameters implied by each of the calibration procedures we use, as well as the changes between equilibria and other information used in our decomposition experiments. We note that some of the changes in technology parameters that these procedures produce (especially procedure 3) are large, and sometimes change sign between skilled and unskilled labour. 
Table 3

Changes in production-side parameters, relative prices and endowments during 1979-95 (\%), and base level of input elasticity of substitution

\begin{tabular}{|c|c|c|c|c|c|c|c|c|c|}
\hline & \multicolumn{9}{|c|}{ Exact Calibration Procedure } \\
\hline & \multicolumn{3}{|c|}{1} & \multicolumn{3}{|c|}{2} & \multicolumn{3}{|c|}{3} \\
\hline & 1979 & 1995 & $\%$ change & 1979 & 1995 & $\%$ change & 1979 & 1995 & $\%$ change \\
\hline \multicolumn{10}{|c|}{ Change } \\
\hline$\delta^{U^{\circ}}$ & 1.00 & 1.17 & 17.2 & 1.00 & 1.00 & 0.00 & 1.00 & 0.23 & -76.9 \\
\hline$\delta^{S}$ & 1.00 & 1.95 & 95.3 & 1.00 & 1.00 & 0.00 & 1.00 & 3.81 & 281.1 \\
\hline$\beta_{M}$ & 0.53 & 0.42 & -21.4 & 0.53 & 0.40 & -26.0 & 0.53 & 0.53 & 0.0 \\
\hline$\beta_{E}$ & 0.38 & 0.28 & -26.7 & 0.38 & 0.26 & -31.9 & 0.38 & 0.38 & 0.0 \\
\hline$\gamma_{M}$ & 17.56 & 17.56 & 0.0 & 17.56 & 24.62 & 40.2 & 17.56 & 24.0 & 36.5 \\
\hline$\gamma_{E}$ & 18.58 & 18.58 & 0.0 & 18.58 & 26.13 & 40.6 & 18.58 & 19.6 & 5.4 \\
\hline$\alpha_{M}$ & 0.68 & 0.73 & 8.3 & 0.68 & 0.73 & 8.3 & 0.68 & 0.73 & 8.3 \\
\hline$\alpha_{E}$ & 0.64 & 0.64 & 0.1 & 0.64 & 0.64 & 0.1 & 0.64 & 0.64 & 0.1 \\
\hline$P_{M} / P_{E}$ & 1.00 & 0.92 & -7.9 & 1.00 & 0.92 & -7.9 & 1.00 & 0.92 & -7.9 \\
\hline $\mathrm{U}$ & 1.00 & 0.75 & -25.0 & 1.00 & 0.75 & -25.0 & 1.00 & 0.75 & -25.0 \\
\hline $\mathrm{S}$ & 1.00 & 1.09 & 9.3 & 1.00 & 1.09 & 9.3 & 1.00 & 1.09 & 9.3 \\
\hline$\rho_{i t t}$ & 1.25 & 1.25 & 0.0 & 1.25 & 1.25 & 0.0 & 1.25 & 1.25 & 0.0 \\
\hline
\end{tabular}




\section{Results}

We have performed decomposition experiments with the model parameterized using the exact double calibration procedures set out above, as well as further experiments using model parameterizations based on inexact calibration methods. For each, we perform decomposition exercises in which we separately evaluate the influences of trade, technology and endowments on observed relative wage change for the UK between 1979 and 1995. We refer to the first of these experiments as 1, 2 and 3. In all these experiments, relative goods prices change over time as do factor endowments, and (through the data and calibration) the output elasticity with respect to the composite labour input, $\alpha_{i t}$. We examine the sensitivity of experiment results to different values of production substitution elasticities, $\rho_{i t}$.

\subsection{Central Case}

Table 4 presents decomposition results for experiments 1,2 and 3. The identifying restrictions used in the first experiment imply that no Hicks-neutral technical change occurs over time, and that technical change is factor-biased. In contrast, the calibration procedures used in experiment 2 removes factor-biased technical change and allow for Hicks-neutral change. In both of these experiments, the production function parameter in each sector $\beta_{i t}$ (the share of unskilled labour in composite labour) varies over time. Experiment 3 allows for both factorbiased and Hicks-neutral technical change, but $\beta_{i t}$ is constant over time. 


\section{Table 4}

\section{UK 1979-1995 wage inequality decomposition experiments under alternative exact calibration procedures}

\section{$\%$ of Wage Inequality Change \\ Attributed to Each Contributing Factor}

Increased trade

Factor-biased technical change

Hicks-neutral technical change

Factor endowment changes

Changes in $\beta_{i t}$

Changes in $\alpha_{i t}$

\section{Calibration Procedure}

$1 \quad 2 \quad 3$

$\begin{array}{lll}17 & 17 & 17\end{array}$

47

0

$-144$

157

$-19$

$0 \quad 211$

$1-49$

$-144 \quad-144$

$183 \quad 0$

$-19-19$

We perform these experiments by alternatively introducing the changes specified in the first column of Table 4 into the base period specification of the model and comparing the resulting model solution to the full observed change. By identifying the separate effects of changes in exogenous variables between periods (such as changes in world prices which generate trade surges), decomposition results show the importance of the factor involved. For changes in trade, results are the same $i$ under all calibration procedures since the size of the trade shock is unique and is not obtained through calibration. Where changes over time are in calibrated technology parameters (as with factor biased technical change), results vary with the calibration procedure used since the size of the change in these parameters depends on the specific procedure employed, as shown in Table 3

While results in Table 4 vary for changes in the calibration method, they suggest that there is a relatively small contribution of trade (17\%) to increased wage inequality over the period. A larger role emerges for factor-biased technical change (procedures 1 and 3), which, in turn, varies significantly depending upon the calibration used. Where changes in share 
parameters, $\beta_{i t}$, are not allowed, factor-biased technical change accounts for more than the observed wage inequality change. Factor endowment changes have large negative effects on wage inequality, but these are offset by the positive effects of changes in share parameters under methods 1 and 2, and by factor-biased technical change under method 3 .

Under procedure 1, factor-biased technical change is responsible for slightly less than half the relative wage change. This is accompanied by larger offsetting positive and negative effects from changes in $\beta_{i t}$ and endowments. Under procedure 3, the contribution of factor-biased technical change is more than twice the observed change in wage inequality, but is offset by the opposite effect generated by both Hicks-neutral technical change and the relative decrease in the endowment of unskilled labour. Changes in the parameter $\alpha_{i t}$ act as an offset to factor-biased technical change in all experiments, though to a much lesser degree.

Results from procedures 1 and 3 thus appear to confirm the finding in the trade and wages literature that skilled-biased technical change is a more significant contributory factor to increased wage inequality than trade. Results from procedure 3 , in which the parameter $\beta_{i t}$ is held constant across periods, also highlight a feature which has figured less prominently in the literature; namely that changes in factor endowments offset new wage inequality associated with trade and factor-biased technical change. This case also shows how other technology-related factors, importantly sector specific technical change, are also non-trivial factors. Finally, results using procedure 3 suggest that the impact of skill-biased technical change on wage inequality could be more significant than existing literature suggests.

Results using procedure 2 are similar to those from procedure 1 in that increases in wage inequality are accounted for mainly by changes in $\beta_{i t}$. Relative to those generated using 
procedure 3, these results point to a smaller role for Hicks-neutral technical change, although changes in $\beta_{i t}$ cannot themselves be interpreted as technical change in a conventional sense.

\subsection{Sensitivity Analysis}

We have also performed sensitivity analyses on the results generated by our central case model specifications by changing the exogenous values set for the elasticity of substitution in production, $\rho_{i t}$, for each of the three exact calibration procedures. Results from cases where $\rho_{i t}=$ 0.5 , and $\rho_{i t}=2.0$ are presented in Table 5 .

\section{Table 5}

\section{Sensitivity Analyses of Model Results to Alternating Values of Elasticities of Substitution in Production}

\begin{tabular}{|c|c|c|c|c|c|c|}
\hline \multirow[t]{2}{*}{$\begin{array}{c}\text { \% of wage inequality change } \\
\text { attributed to each contributing } \\
\text { factor }\end{array}$} & \multicolumn{2}{|c|}{$\rho_{i t}=0.5$} & & \multicolumn{3}{|c|}{$\begin{array}{c}\text { Calibration } \\
\text { Procedure }\end{array}$} \\
\hline & 1 & 2 & 3 & 1 & 2 & 3 \\
\hline Increased trade & 37 & 37 & 37 & 11 & 11 & 11 \\
\hline Factor-biased technical change & -22 & 0 & 241 & 164 & 0 & 159 \\
\hline Hicks-neutral technical change & 0 & -16 & 490 & 0 & 2 & -3 \\
\hline Factor endowment changes & -385 & -385 & -385 & -88 & -88 & -88 \\
\hline Change in $\beta_{i t}$ & 274 & 267 & 0 & -9 & 155 & 0 \\
\hline Change in $\alpha_{i t}$ & -45 & -45 & -45 & -12 & -12 & -12 \\
\hline
\end{tabular}

For $\rho_{i t}=0.5$, the magnitude of the trade effect is double that of the central case, while the contribution of factor-endowment changes almost trebles. This is because as the elasticities of substitution in production fall, price and wage responses to shocks are larger and quantity are responses smaller. The size of the effects attributed to factor-biased technological change alters little in one of the cases (3), but its sign is reversed in another (1). Using procedure 3, with $\rho_{i t}=$ 0.5 , the size of the Hicks-neutral technical change effect increases substantially, and becomes a 
major factor in offsetting the effects of trade and factor-biased technical change on increased wage inequality.

Increasing $\rho_{i t}$ to 2.0 also produces significant changes in results, most notably in the size of the factor-biased technical change effect, which increases sharply relative to procedure 1, and that of changes in factor endowments, which are reduced by about half relative to the central case. These results, taken together with those using the central case model parameterizations, suggest that Hicks-neutral technical change tends to reduce wage inequality, but the magnitude of the effect is small.

Taken as a set, these results seem to indicate that the qualitative pattern of the decomposition result in our central case results remains unchanged in terms of relative rankings of various factors acting on wage inequality change as we move across different model parameterizations, but there are clearly significant quantitative changes. Our finding above that factor-biased technological change has played a larger role in generating increased wage inequality than previously suggested in the literature, and that changes in factor endowments have been a key offsetting force, seems to remain reasonably robust—as does the relatively small contribution of trade-related factors.

\subsection{Decomposition with Inexact Calibration}

We have also generated decomposition results using the inexact calibration procedure described above. To implement this, we isolate the effects of factor-biased technical change by using a model calibration in which both Hicks-neutral technical change parameters, $\gamma_{i t}$, and factor shares in production, $\beta_{i t}$, remain constant across periods. 


\title{
Table 6 \\ Wage inequality decomposition with inexact calibration
}

\section{$\%$ of Wage Inequality Change \\ Attributed to Each Contributing Factor}

\author{
Increased trade \\ 17 \\ Factor-biased technical change \\ 183 \\ Factor endowment changes $\quad-144$ \\ Change in $\alpha_{i t} \quad-19$
}

Results again highlight both the significance of the contribution of factor-biased technical change to wage inequality and the offsetting effect coming from changes in factor endowments (Table 6). They are similar to those using exact calibration procedure 3 (Table 4). This is because, as indicated earlier, the inexact calibration case is in fact a variant of exact calibration procedure 3: the former corresponds to the latter but without Hicks-neutral technical change. And since the effect on Hicks-neutral technical change under exact calibration procedure 3 is relatively small (Table 4), the difference between the two cases is not very pronounced. As pointed out earlier, the inexact calibration case can also be seen as a variant of exact calibration procedure 1 , with the difference being that under the former the share parameters $\beta_{\text {it }}$ do not change over time. And since changes in the $\beta_{\text {it }}$ have a large impact on wage inequality (Table 4), the difference between the two cases is now substantial. ${ }^{4}$

\footnotetext{
${ }^{4}$ Note that, compared to exact calibration procedure 3, the effect of factor-biased technical change under inexact calibration is reduced because under the former the impact of Hick-neutral technical change (which the latter now implicitly incorporates) is negative. Compared to exact calibration procedure 1, however, factor-biased technical change has, with inexact calibration, a stronger impact on inequality since under the former the change in $\beta$ it (now implicitly incorporated by the latter) is inequality increasing.
} 


\section{Summary and Conclusions}

In this paper we present techniques for performing ex post decomposition analysis using calibrated multi-sector general equilibrium models; applying them to an analysis of the sources of increases in wage inequality in the UK between 1979 and 1995. The novelty in our technique lies in calibrating a general equilibrium model to two (or more) observations, and generating parameter values which allow the model to reflect the influences of various exogenous changes which jointly contribute to the observed outcome being decomposed. Relative to existing trade and wages literature, we employ a full structural form general equilibrium model rather than an estimated reduced form.

We show how the calibrations involved can be performed in ways that are either exact or inexact. These procedures allow for direct estimation of the main sources of increased wage inequality discussed in recent literature (increased trade and factor-biased technical change), as well as of other technology-related factors (including sector-biased technical change) and changes in factor endowments.

Our results suggest that between 1979 and 1995 the role of factor-biased technological change in generating increased wage inequality in the UK has been even larger than suggested by other results in previous literature. We also find that changes in factor endowments have played a major role in partially offsetting pressures for increased wage inequality from trade and factor-biased technological change $-\mathrm{a}$ feature that has received less attention in existing literature. Our estimate of the contribution of increased trade to UK wage inequality is small, and consistent with results from earlier literature. 


\section{References}

Abrego, L. and J. Whalley (2000), "The Choice of Structural Model in Trade-Wages Decompositions." Review of International Economics, Vol. 9, No. 3 (August).

Anderton, B. and P. Brenton (1998) "The Dollar, Trade, Technology and Wage Inequality in the USA,” CEPS, Brussels, mimeo.

Baldwin, R.E. and G.G. Cain (1997), "Shifts in US Relative Wages: The Role of Trade, Technology and Factor Endowments," NBER Working Paper No. 5934.

Berman, E., J. Bound and Z. Griliches (1994), "Changes in the Demand for Skilled Labour within US Manufacturing: Evidence from Annual Survey of Manufactures," Quarterly Journal of Economics 109: 367-98.

Bound, J. and G. Johnson (1992), "Changes in the Structure of Wages in the 1980's: An Evaluation of Alternative Explanations." American Economic Review 82: 371-92.

Burtless, G. (1995), "International Trade and the Rise in Earnings Inequality," Journal of Economic Literature 33: 800-816.

Card, D. (1998), "Falling Union Membership and Rising Wage Inequality: What's the Connection?" NBER Working Paper No. 6520.

Dawkins, C. T.N. Srinivasan, and J. Whalley (2000), "Calibration" in ed. E.C.Leamer and J. Heckman, Handbook of Econometrics, North-Holland.

Feenstra, R. and G. Hanson (1996), "Globalization, Outsourcing and Wage Inequality," American Economic Review, May, 240-45.

Feenstra, R. and G. Hanson (1999), "The Impact of Outsourcing and High-Technology Capital on Wages: Estimates for the United States, 1979-90," Quarterly Journal of Economics 113: 907-40.

Fogel, R. (1964), Railways and American Economic Growth. Baltimore: John Hopkins Press.

Fortin, M. and L. Thomas (1997) "Institutional Changes and Rising Wage Inequality," Journal of Economic Perspectives 11: 75-96.

Francois, F. and D. Nelson (1998) "Trade, Technology and Wages: General Equilibrium Mechanics," Economic Journal 108: 1483-1499.

Gottschalk, P. and T. Smeeding (1997) "Cross National Comparisons of Earnings and Income Inequality," Journal of Economic Literature 35: 633-87. 
Harrigan, J. and R. Balaban (1999) "US Wages in General Equilibrium: The Effects of Prices, Technology, and Factor Supplies, 1963-1991,” NBER Working Paper No. 6981.

Haskel, J. and M. Slaughter (1998), "Does the Sector Bias of Skilled-Biased Technical Change Explains Changing Wage Inequality?" NBER Working Paper No. 6565.

Haskel, J. and M. Slaughter (1999), "Trade Technology and UK Wage Inequality." NBER Working Paper No. 6978.

Jones, R.W. (1971), "A Three-Factor Model in Theory, Trade and History." In J.N. Bhagwati, R.A. Mundell and J. Vanek, Trade Balance of Payments and Growth: Essays in Honor of Charles P. Kindleberger. Amsterdam: North-Holland.

Johnson, H.G. (1966), "Factor Market Distortions and the Shape of the Transformation Frontier." Econometrica 34: 686-98.

Krugman, P. (2000), “Technology, Trade and Factor Prices” Journal of International Economics 50: $51-71$.

Leamer, E. (1998), “In Search of Stolper-Samuelson Linkages between International Trade and Lower Wages." In S. M. Collins (ed.) Imports, Exports, and the American Worker. Washington, D.C.: Brookings Institution.

Machin, S. and J. van Reenen (1998) "Technology and Changes in Skill Structure: Evidence from Seven OECD Countries.” Quarterly Journal of Economics 113: 1215-44.

Murphy, K. and F. Welch (1989), "Wage Premiums for College Graduates: Recent Growth and Possible Explanations." Educational Researcher 18: 17-26.

Mussa, M. (1974), "Tariffs and the Distribution of Income: The Importance of Factor Specificity, Substitutability, and Intensity in the Short and Long Run." Journal of Political Economy 82: 1191-1204.

OECD (1995), The OECD Input-Output Database. OECD: Paris.

Office for National Statistics (1996), Labour Market Trends (May issue). London: ONS.

Office for National Statistics (1981-82), Employment Gazette (various issues). London: ONS.

Office for National Statistics (1996), Labour Market Trends (May issue). London: ONS.

Office for National Statistics (1997a), United Kingdom National Accounts. London: ONS.

Office for National Statistics (1997b), Input-Output Balances for the UK. London: ONS.

Sachs, J. and H. Shatz (1994), "Trade and Jobs in US Manufacturing." Brookings Papers of Economic Activity: 1-84. 
Samuelson, P.A. (1971), “Ohlin Was Right.” Swedish Journal of Economics 73: 365-84.

Shoven, J. and J. Whalley (1992), Applying General Equilibrium. Cambridge: Cambridge University Press.

Slaughter, M. (1999), “Globalization and Wages: A Tale of Two Perspectives World Economy 22: 609-29.

Solow, R. (1957), "Technical Change and the Aggregate Production Function." Review of Economics and Statistics 39: 312-20.

Wood, A. (1994), North-South Trade, Employment and Inequality, Oxford: Clarendon Press. 